\title{
REVIEW
}

Open Access

\section{Effects of whey protein on glycemic control and serum lipoproteins in patients with metabolic syndrome and related conditions: a systematic review and meta- analysis of randomized controlled clinical trials}

Elaheh Amirani ${ }^{1}$, Alireza Milajerdi ${ }^{2}$,̌eljko Reiner ${ }^{3,4}$, Hamed Mirzaei ${ }^{1}$, Mohammad Ali Mansournia $^{5}$ and Zatollah Asemi ${ }^{* *}$ (i)

\begin{abstract}
Background: This systematic review and meta-analysis aimed to assess the effects of whey protein on serum lipoproteins and glycemic status in patients with metabolic syndrome (MetS) and related disorders.

Methods: Online databases, such as Web of Science, Cochrane Library, PubMed and Scopus were systematically searched by two independent authors from inception until 30th April 2020 for English randomized clinical trials investigating the efficacy of whey protein administration in subjects with Mets or related conditions on the parameters of glycemic and lipid control compared to certain control. In order to evaluate the included studies' methodological quality, Cochrane Collaboration risk of bias tool was applied. Using Cochrane's Q test and I-square $\left(I^{2}\right)$ statistic, the included trials' heterogeneity was also examined. Using a random-effects model, data were pooled, and weighted mean difference (WMD) was considered as the overall effect size.
\end{abstract}

Results: Twenty-two studies were selected to be included in this meta-analysis. Consumption of whey protein resulted in significant reduction of HbA1c (WMD: -0.15; 95\% Cl: - 0.29, - 0.01) insulin (WMD: -0.94; 95\% Cl: - 1.68, 0.21 ) and homeostasis model assessment-estimated insulin resistance (HOMA-IR) (WMD: -0.20; 95\% Cl: - 0.36, 0.05). A significant reduction in triglycerides levels (WMD: $-17.12 ; 95 \% \mathrm{Cl}:-26.52,-7.72)$, total cholesterol (WMD: -10.88; 95\% Cl -18.60, - 3.17), LDL-cholesterol levels (WMD: -8.47 95\% Cl: - 16.59, - 0.36) and total cholesterol/HDLcholesterol ratio (WMD: $-0.26 ; 95 \% \mathrm{Cl}:-0.41,-0.10)$ was found as well.

\footnotetext{
*Correspondence: asemi_r@yahoo.com; Asemi_r@yahoo.com

${ }^{1}$ Research Center for Biochemistry and Nutrition in Metabolic Diseases, Institute for Basic Sciences, Kashan University of Medical Sciences, Kashan, Iran

Full list of author information is available at the end of the article
}

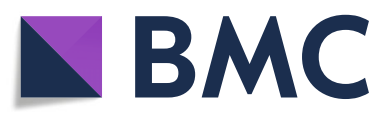

() The Author(s). 2020 Open Access This article is licensed under a Creative Commons Attribution 4.0 International License, which permits use, sharing, adaptation, distribution and reproduction in any medium or format, as long as you give appropriate credit to the original author(s) and the source, provide a link to the Creative Commons licence, and indicate if changes were made. The images or other third party material in this article are included in the article's Creative Commons licence, unless indicated otherwise in a credit line to the material. If material is not included in the article's Creative Commons licence and your intended use is not permitted by statutory regulation or exceeds the permitted use, you will need to obtain permission directly from the copyright holder. To view a copy of this licence, visit http://creativecommons.org/licenses/by/4.0/ The Creative Commons Public Domain Dedication waiver (http://creativecommons.org/publicdomain/zero/1.0/) applies to the data made available in this article, unless otherwise stated in a credit line to the data. 
(Continued from previous page)

Conclusions: This meta-analysis suggests that supplementation with whey protein had beneficial effect on several indicators of glycemic control and lipid parameters in patients with MetS and related conditions.

Keywords: Whey protein, Insulin resistance, Metabolic syndrome, Triglycerides, Total cholesterol, LDL-cholesterol, HDL-cholesterol

\section{Background}

Obesity, atherogenic dyslipidemia, arterial hypertension (HTN) and insulin resistance are the most important risk factors of cardiovascular disease (CVD). Often there is a clustering of these risk factors in one patient which is then called metabolic syndrome (MetS). MetS increases also the risk of type 2 diabetes mellitus (T2DM) [1]. It is estimated that over $20 \%$ of adults in Western countries have MetS with a clear tendency to increase $[2,3]$. Many studies in healthy populations as well as in patients have reported that higher dairy consumption decreases the risk of MetS or some of the components of MetS and diabetes $[4,5]$. It has been documented that specific components of dairy, including calcium, other minerals, and proteins such as whey proteins and casein [6], may have favorable effects on these risk factors.

There are different types of whey protein such as concentrate, isolate, hydrolysate and native whey protein, which come in multiple formulations including milk, milk powder and specialized formula with a higher content of certain amino acids [7]. This protein seems to have anti-inflammatory effects, beneficial effects on immunity, blood pressure and cholesterol as well as some anticancer properties [8]. Some favorable metabolic effects of whey protein may result from increasing the release of hormones including glucagon like-peptide 1 (GLP-1), leptin, and cholecystokinin, and the reduction of ghrelin and therefore the result might be weight reduction. Biological benefits of whey protein also might be associated to its nutritional components, especially cysteine and branched-chain amino acids (BCAAs). Whey protein also stimulates immune function, immunoglobulins and antioxidants [7].

The effects of whey protein on glycemic control and serum lipoproteins are controversial. In a study in which patients with MetS were taking yogurt fortified with whey protein during 10-weeks, it significantly reduced triglycerides levels and insulin resistance, and significantly increased HDL-cholesterol levels [9]. Supplementation with whey proteins during 12 weeks in overweight and obese subjects was associated with a significant decrease in total cholesterol and LDL- cholesterol and an improvement in fasting insulin concentrations and homeostasis model assessment of insulin resistance (HOMA-IR) scores [10]. In a meta-analysis by Wirunsawanya et al. [11], which included trials on overweight and obese patients, whey protein administration improved some CVD risk factors such as systolic and diastolic blood pressure, fasting plasma glucose (FPG), HDL-cholesterol, and total cholesterol levels, but did not influence other metabolic parameters.

The results of different studies which analyzed the impact of different types and amounts of whey protein on metabolic parameters were controversial. The aim of this systematic review and meta-analysis was to analyze the current information concerning whey protein effects on serum lipoproteins and glycemic control in patients with MetS and associated disorders like HTN, obesity, and diabetes mellitus.

\section{Materials and methods}

Search strategies and selected outcomes

Protocol of study was registered in international prospective register of systematic reviews (PROSPERO) (ID: CRD42020203067). In order to find and include relevant investigations published from inception until 30th April 2020, international databases, such as Web of Science, PubMed, Scopus and Cochrane Library were searched for studies evaluating the effects of whey protein supplementation among patients with MetS and associated disorders. PROSPERO database was searched to identify similar records. The strategy of search and keywords are presented in Supplemental file- Table 1; This meta-analysis was conducted to determine the efficacy of whey protein on the following outcomes: parameters of glycemic control including fasting plasma glucose (FPG), fasting insulin levels, HOMA-IR, Hemoglobin A1c (HbA1c), and lipid profiles including triglycerides levels, total-, high density lipoprotein (HDL-), low density lipoprotein (LDL-), and very density lipoprotein (VLDL-) cholesterol levels in fasting state and the total/HDL-cholesterol ratio.

\section{Inclusion and exclusion criteria}

In this meta-analysis, randomized controlled trials (RCTs) which fulfilled the following criteria for participants, interventions, comparisons, outcomes, and study design (PICOS) were included: 1) Participants: human subjects with MetS or conditions related to this syndrome. 2) Intervention: whey protein administration. 3) Comparisons: control, including placebo, carbohydrate supplementation, usual diet or no intervention. 4) Outcomes: serum lipoproteins and glycemic status. 5) Study design: parallel or cross-over design. In addition, data 
need to be presented as mean/median with standard deviation (SD) or standard error (SE) or related 95\% confidence intervals (CIs) or interquartile range (IQR) for both intervention and control groups. Relevant articles which were written English were included. Inclusion criteria for MetS were: 3 or more of these parameters - increased waist circumference (according to specific cut point for population), triglycerides levels $\geq 150 \mathrm{mg} / \mathrm{dl}$, blood pressure $\geq 130 / 85 \mathrm{mmHg}$, FPG concentrations $\geq 100 \mathrm{mg} / \mathrm{dl}$, and HDL-cholesterol values $<40 \mathrm{mg} / \mathrm{dl}$ for men and $<50 \mathrm{mg} / \mathrm{dl}$ for women [12]. Dyslipidemia, overweight and obesity $(\mathrm{BMI} \geq 25)$, insulin resistance, diabetes, HTN, polycystic ovary syndrome (PCOS), nonalcoholic fatty liver disease, and CVD were considered as conditions related to MetS. Studies that compared whey protein with other protein supplements (casein, gelatin and etc.), trials without control group, case reports, observational studies, animal experiments and in vitro studies were excluded. Concerning studies designed to analyze exercise training, those which compared whey protein effects against exercise also were excluded.

\section{Data extraction and quality assessment}

Based on the eligibility criteria, two authors (HM and EA) independently screened the articles. At the beginning, studies' abstracts and titles were reviewed. As the second step, to ensure that a study is suitable for this meta-analysis, relevant articles' full-text was evaluated. In case of relevant studies with incomplete data or without full text, a request was emailed to correspond author. Any disagreement was resolved by the judgment of the third author (ZA).

The following data were extracted from selected trials: the authors' name, study duration, whey protein type and dosage, exercise training, study design, study location, sample size, publication year, the type of the disease, the SD and mean for serum lipoproteins and glycemic control in each treatment group. For incorporating cross-over trials which reporting data of each period separately, only data from the first period were included [13]. For studies presenting median and IQR, mean was estimated by (first quartile + third quartile) $/ 2$, and SD was estimated by (third quartile - first quartile)/ 1.35 [14]. For studies presenting 95\% CI, SE was estimated by (upper limit - lower limit)/3.92 and SD was calculated as SE $\times \sqrt{ } \mathrm{n}$ [15]. Unit conversion of $\mathrm{mmol} / \mathrm{L}$ to $\mathrm{mg} / \mathrm{L}$ was done using Units lab online data base [16]. Concerning a previous meta-analysis by Guasch-Ferré et al. [17], three categories based on control group of the included studies were considered: 1) placebo product, 2) non-intervention control like usual diet or no supplementation, and 3) carbohydrate supplementation like maltodextrin or sugar. These categories were used to explore the potential heterogeneity due to different types of controls. Quality of Included RCTs was evaluated by same independent authors using Cochrane tool. In addition, the quality of findings was assessed using Grading of Recommendations Assessment, Development and Evaluation (GRADE) approach.

\section{Data synthesis and statistical analysis}

Whey protein effects on the alterations of the analyzed parameters were calculated. For pooling data to determine effect sizes, weighted mean difference (WMD) with 95\% $\mathrm{CI}$ was utilized. The change score method was used to calculate the effect size of whey protein on the analyzed parameters. The fixed-effect model was used to report the pooled effect sizes using $95 \% \mathrm{CI}$. In cases of high betweenstudy heterogeneity, we used random-effect model to analyze data. Furthermore, meta-regression was done to explore any dose-response association between outcomes of interest and duration of supplementation.

\section{Heterogeneity and publication bias}

Heterogeneity of included studies was evaluated using Cochrane's Q test and I-square test $\left(\mathrm{I}^{2}\right.$ greater than $50 \%$ showing significant heterogeneity) $[18,19]$. In cases of high between-study heterogeneity, we stratified the included studies based on participants' age to studies that recruited subjects with a mean age of 20-65 years (exclusively adults) and those done on subjects aged $\geq 20$ (including both adults and elderly subjects). In addition, a subgroup analysis was done concerning the participants' health condition taking into the consideration studies on healthy participants and studies on patients with any chronic disease, including diabetes, CVD, and cancers. The other subgroup analyses were done based on intervention type (whey protein/isolated whey protein), study duration $(<12$ weeks $/ \geq 12$ weeks), and study sample size $(n<50 / n \geq 50)$. The cut-points for the study duration and sample size were selected based on sufficient number of studies which were included in each subgroup. In order to assess the effects of heterogeneity on outcomes, 95\% predictive intervals (PI) also were estimated manually [20]. Publication bias was evaluated by the funnel plot and tested for statistical significance using the Egger's test [21]. Both STATA 11.0 (Stata Corp., College Station, TX) and Review Manager 5.3 (Cochrane Collaboration, Oxford, UK) were applied for data analysis.

\section{Results}

\section{Characteristics of included studies}

Twenty-two studies were included in this systematic review and meta-analysis. These studies were published between 2007 and 2019. Flow-diagram for study selection is shown in Fig. 1. One thousand one hundred three subjects, 576 in intervention and 527 in control groups, were enrolled in included studies. Characteristics of 
Articles identified through

electronic database search $(\mathrm{n}=1308)$

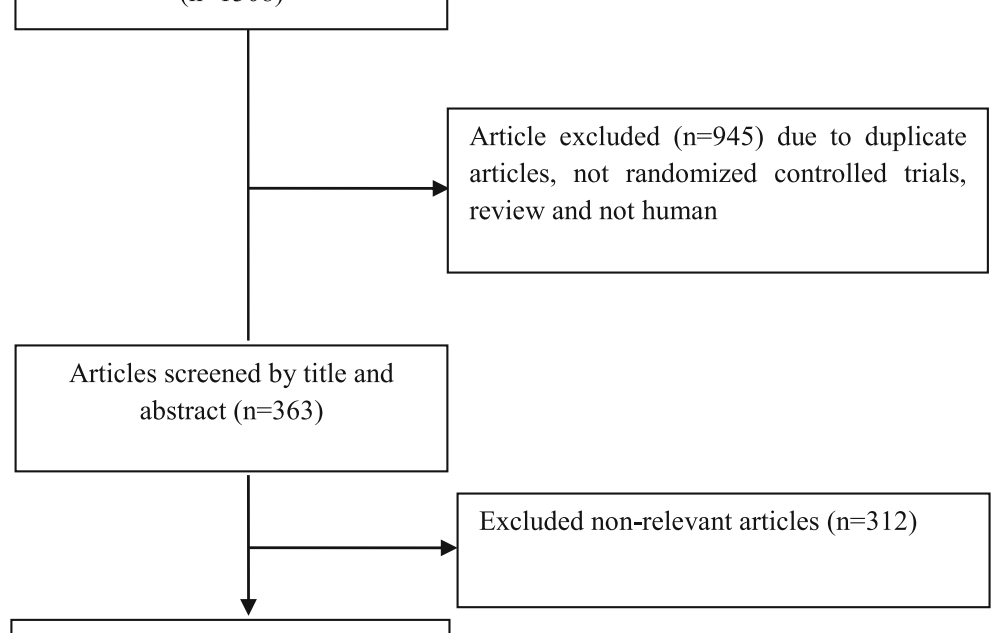

Full text articles assessed for eligibility $(\mathrm{n}=51)$

Articles excluded ( $\mathrm{n}=29)$ :

1. No relevant outcome reported $(\mathrm{n}=16)$

2. No control group $(n=3)$

3. Comparison of whey protein with other

protein supplementation $(\mathrm{n}=7)$

4- Data as median and range $(\mathrm{n}=1)$

5- Not MetS and related conditions $(\mathrm{n}=2)$

Studies included in this study

$(\mathrm{n}=22)$

Fig. 1 Literature search and review flowchart for selection of studies

included studies are summarized in Table 1. Participants had chronic diseases like HTN [22, 28, 31, 40] and T2DM [33, 36, 38] in some studies. The intervention period varied from 4 weeks to 24 weeks. Whey protein supplements were administrated in dosages which varied from $70 \mathrm{mg} / \mathrm{d}$ to $90 \mathrm{~g} / \mathrm{d}$. In 5 studies, a dosage of $\leq 20 \mathrm{mg} / \mathrm{d}$ was used $[9,23,28,29,32]$. Six trials used whey protein in dosages between 20 and $\leq 40 \mathrm{mg} / \mathrm{d}$ [25, 30, 33, 36, 38, 40]. Five other studies used it at a daily dose between 40 and $60 \mathrm{mg}$ $[10,26,31,35,41]$. Moreover, a dosage $\geq 60 \mathrm{mg} / \mathrm{d}$ of whey protein was used in one study [27]. Whey protein also was provided at daily dosages of $0.4 \mathrm{~g} / \mathrm{kg}$ [39] and 0.5 $\mathrm{g} / \mathrm{kg}$ body weight [34] in other studies. Three studies did not report the amount of whey protein used in their interventions [22, 24, 37]. Eight studies used isolate $[10,24,27,28,31,37-39]$ and 4 studies used concentrate whey protein $[33,34,36,40]$. Combined isolate plus concentrate [30], hydrolysate [41], and intact [23] whey protein was reported each in one trial. Other studies did not report the type of whey protein.

Among studies analyzed in this meta-analysis concerning the significance of between group changes for glycemic parameters, significant decrease of FPG was reported in one study [33], while it was unaffected by treatment in 12 studies $[9,22,24,27,30-32,34,35,38,40,41]$, and it was increased in two studies $[29,39]$. A significant decrease of insulin was shown in one study [9], while it was unaffected by treatment in 9 studies [22, 24, 29-32, 34, 35, 38]. In addition, a significant decrease of HOMA-IR was demonstrated in one study [9], while it was unaffected by treatment in 9 studies [22, 24, 29-32, 34, 35, 38]. A significant 


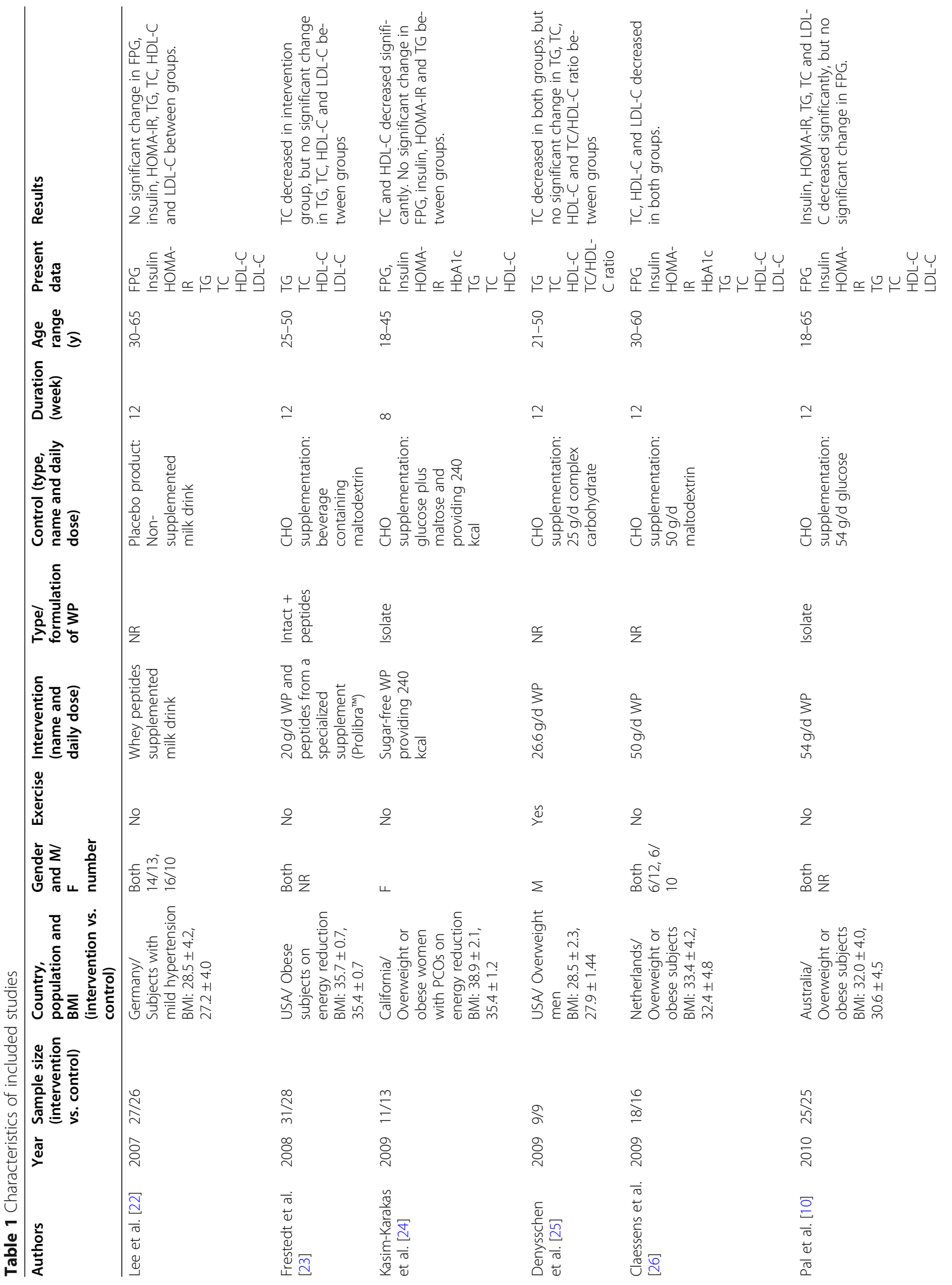




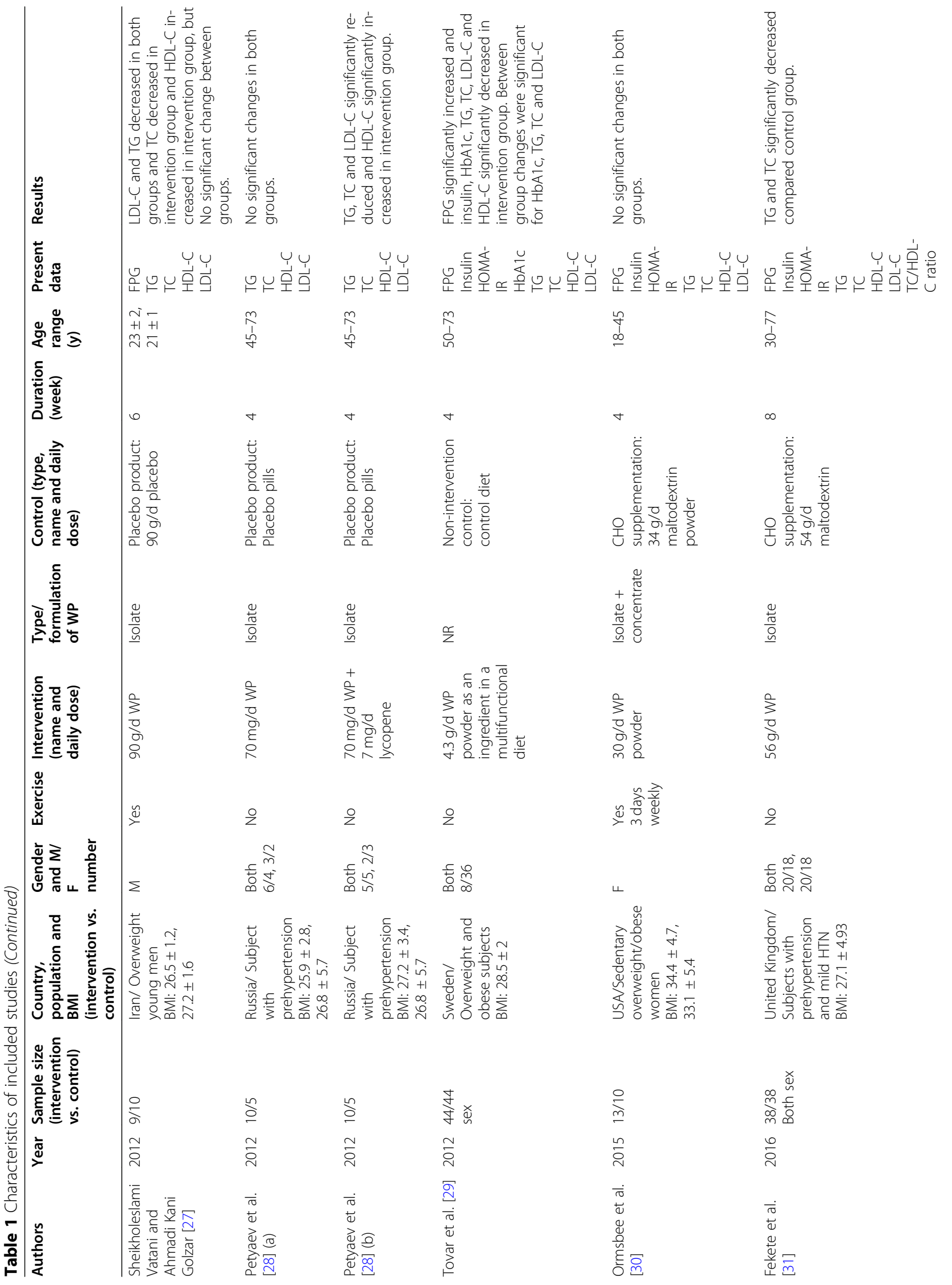




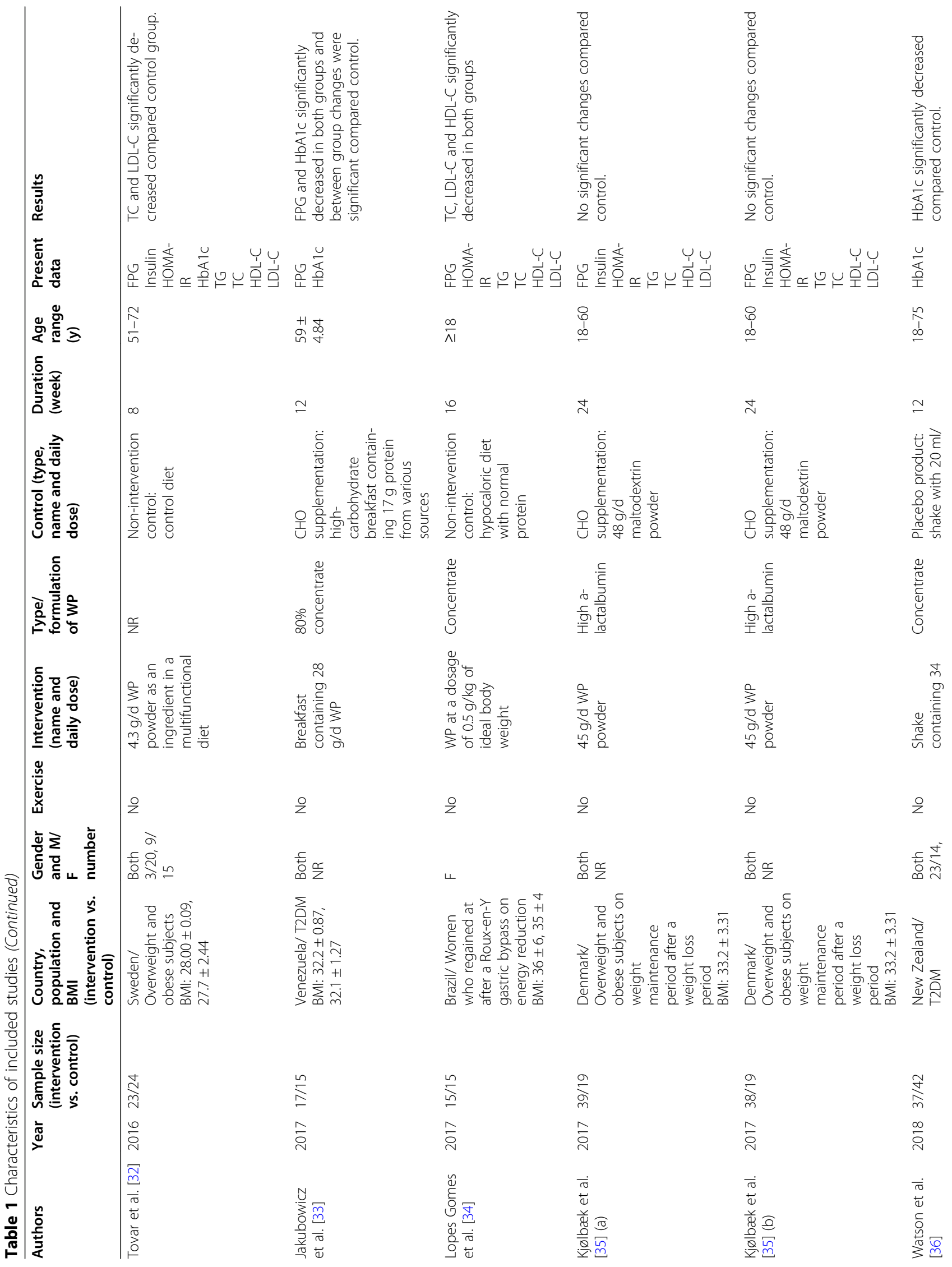




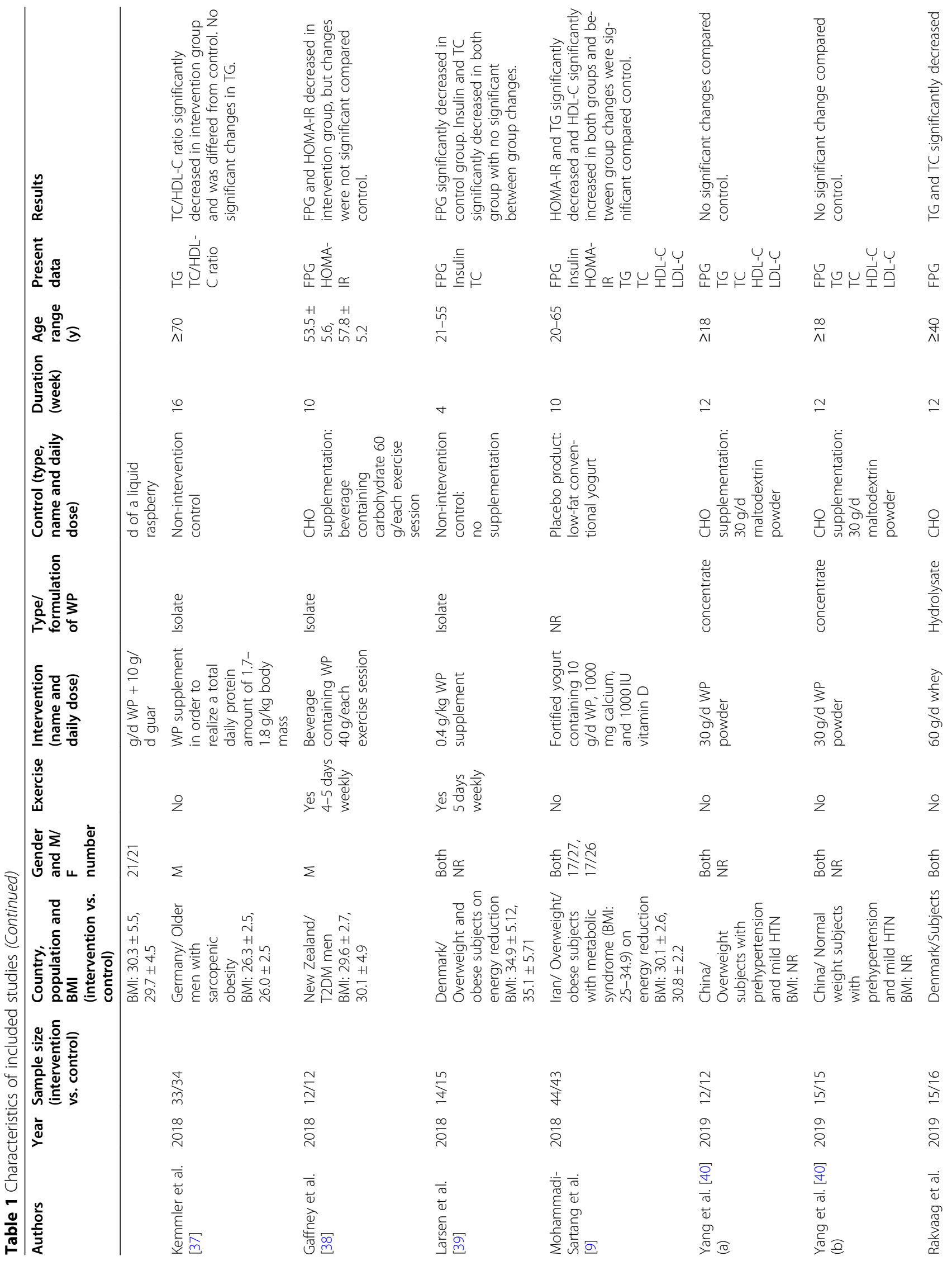




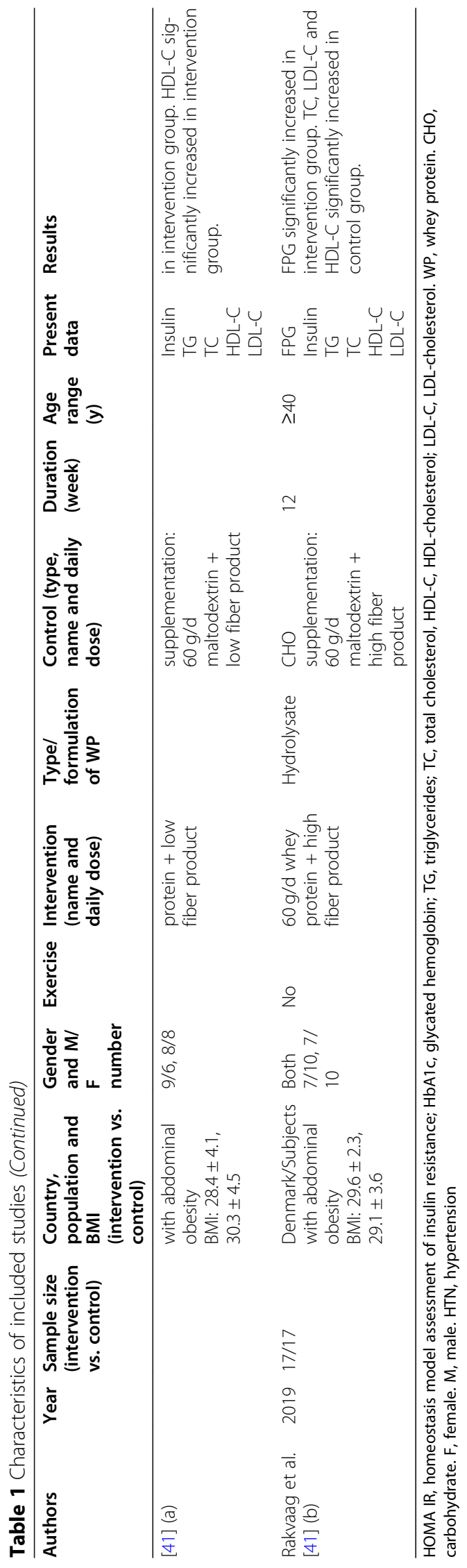


decrease of HbA1c was shown in 3 studies [29, 33, $36]$, while it was unaffected by treatment in 2 studies [24, 32]. However, 2 studies did not report the significance of between group changes for indicators of glycemic control [10, 26].

Among studies analyzed in this meta-analysis concerning the significance of between group changes for lipids and lipoproteins, a significant decrease of triglycerides was proven in 3 studies [9, 29, 31], and 2 effect sizes [41] (a) and [28] (b), while it was unaffected by treatment in 10 studies [22-25, 27, 30, 32, 34, 35, 37, 40], and 2 effect sizes [41] (b), and [28] (a). A significant decrease of total cholesterol was shown in 5 studies [24, 25, 29, 31,32], and one effect size [28] (b), while it was unaffected by treatment in 10 studies [9, 22, 23, 27, 30, 34, 35, 39-41], and one effect size [28] (a). A significant decrease of LDL-cholesterol occurred in 2 studies [29, 32], and one effect size [28] (b), while it was unaffected by treatment in 11 studies $[9,22,23,25,27,30,31,34,35,40,41]$, and one effect size [28] (a). A significant increase of HDL-cholesterol was shown in one study [9], and one effect size [28] (b), while it was unaffected by treatment in 12 studies [22-24, 27, 29-32, 34, 35, 40, 41], and decreased in one study [24]. A significant decrease of total-/HDL-cholesterol ratio was demonstrated in one study [37], while it was unaffected by treatment in two studies [25, 32]. However, 2 studies did not report the significance of between group changes for lipids and lipoproteins $[10,26]$.

\section{Quality assessment}

In the present meta-analysis, the quality of included studies was assessed using Cochrane tool. Based on the components of quality assessment tool, 17 studies were at low risk in term of random sequence generation. For allocation concealment, 14 studies were found to be at low risk, also 13 studies were considered at low risk in term of blinding of participants and personnel. Five studies were at low risk in the aspect of blinding of outcome assessment. In addition, in term of incomplete outcome data, selective reporting and other sources of bias, 22, 15 and 17 studies were considered at low risk, respectively (Supplemental file- Table 2).

\section{The effects of whey protein on glycemic control}

Consumption of whey protein resulted in significant reduction of insulin (12 studies with 14 effect sizes) (WMD: -0.94; 95\% CI: - 1.68, - 0.21) (Table 2 \& Fig. 2b), HOMA-IR (12 studies with 13 effect sizes) (WMD: -0.20 ; 95\% CI: $-0.36,-0.05$ ) (Table 2 \& Fig. 2c) and HbA1c (6 studies) (WMD: -0.15; 95\% CI: $-0.29,-0.01$ ) (Table 2 \& Fig. 2d). Whey protein intake did not have any effect on FPG (17 studies with 20 effect sizes) (WMD: -0.61; 95\% CI: - 2.83, 1.62) (Table 2 \& Fig. 2a). The quality of evidence was moderate for insulin and HbA1c in GRADE system. Also, FPG, HOMA-IR had a low evidence quality of evidence (Supplemental fileTable 3). After adjustment, PI indicated that results were insignificant for FPG (95\% PI: - 3.05, 1.79), insulin (95\%PI: - 1.91, 0.87), HOMA-IR (95\%PI: - 0.60, 0.09) and HbA1c (95\%PI: - 0.30, 0.01).

In the subgroup analysis of FPG, a significant change was seen in all subgroups except for participants' age (adults) (WMD: -0.30; 95\% CI: - 1.29, 0.69) and in studies which used isolated whey protein (WMD: 0.35; 95\% CI: $-1.57,2.28$ ), placebo (WMD: -1.22 ; 95\% CI: -3.33 , 1.43) and carbohydrate supplementation as control (WMD: -0.73; 95\% CI: - 1.61, 0.15) (Table 3). Whey protein also reduced HbA1c concentrations in all subgroups. Whey protein intake did not have any effect on insulin levels in studies performed on adults + elderly (WMD: $-0.34 ; 95 \% \mathrm{CI}:-0.74,0.07$ ) and those which used a non-intervention controls (WMD: -0.30 ; 95\% CI: $-0.81,0.21$ ). In a subgroup analysis of HOMA-IR, a

Table 2 The effects of whey protein intake on glycemic control and serum lipoproteins

\begin{tabular}{|c|c|c|c|c|c|}
\hline \multirow[t]{2}{*}{ Variables } & \multirow{2}{*}{$\begin{array}{l}\text { Number } \\
\text { of effect } \\
\text { sizes }\end{array}$} & \multirow{2}{*}{$\begin{array}{l}\text { Weighted } \\
\text { mean } \\
\text { difference }\end{array}$} & \multirow[t]{2}{*}{$\mathrm{Cl} 95 \%$} & \multicolumn{2}{|c|}{ Heterogeneity } \\
\hline & & & & $\mathrm{I}^{2}(\%)$ & $P$ - value heterogeneity \\
\hline$\overline{\mathrm{FPG}}$ & 20 & -0.61 & $-2.83,1.62$ & 90.0 & $<0.001$ \\
\hline $\mathrm{HbA1C}$ & 6 & -0.15 & $-0.29,-0.01$ & 91.3 & $<0.001$ \\
\hline Insulin & 14 & -0.94 & $-1.68,-0.21$ & 62.9 & $<0.001$ \\
\hline HOMA-IR & 13 & -0.20 & $-0.36,-0.05$ & 67.2 & $<0.001$ \\
\hline $\mathrm{TC}$ & 22 & -10.88 & $-18.60,-3.17$ & 92.5 & $<0.001$ \\
\hline TG & 22 & -17.12 & $-26.52,-7.72$ & 91.6 & $<0.001$ \\
\hline LDL & 19 & -8.47 & $-16.59,-0.36$ & 94.3 & $<0.001$ \\
\hline $\mathrm{HDL}$ & 21 & -0.13 & $-1.74,1.48$ & 94.3 & $<0.001$ \\
\hline $\mathrm{TC} / \mathrm{HDL}$ & 3 & -0.26 & $-0.41,-0.10$ & 00.0 & 0.53 \\
\hline
\end{tabular}

HOMA IR homeostasis model assessment of insulin resistance, HbA1c glycated hemoglobin, TG triglycerides, TC total cholesterol, $H D L-C$ HDL-cholesterol, LDL-C LDL-cholesterol 


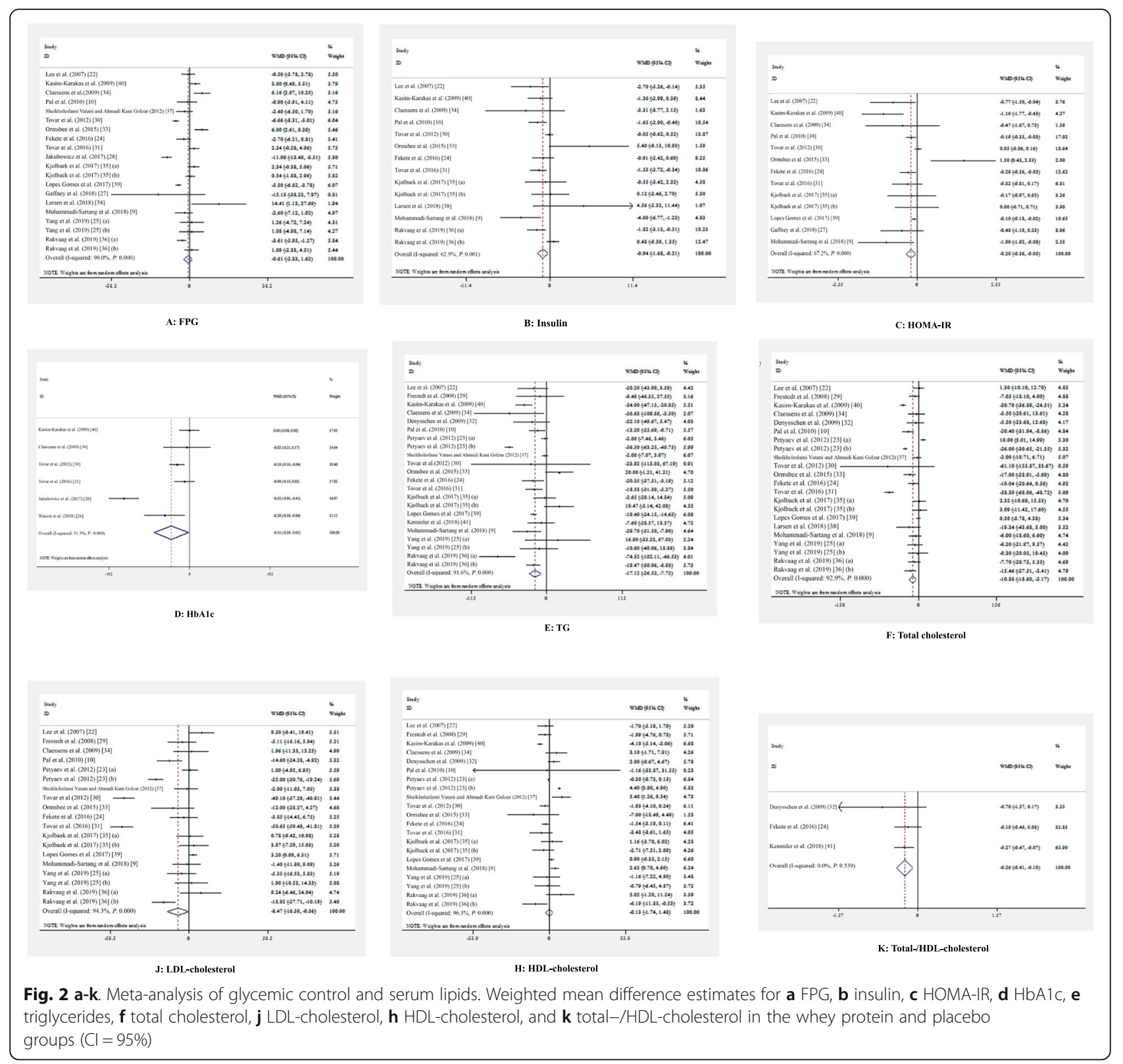

significant change was seen in all subgroups except for studies with a duration < 12 weeks (WMD: -0.04; 95\% CI: $-0.14,0.06$ ) and sample size $\geq 50$ (WMD: -0.07 ; $95 \%$ CI: $-0.16,0.01)$ or studies which used non-intervention controls (WMD: -0.06; 95\% CI: - 0.12, 0.01).

\section{The effects of whey protein on serum lipoproteins}

A significant reduction of triglycerides levels (18 studies with 22 effect sizes) (WMD: -17.12; 95\% CI: - 26.52, 7.72) (Table 2 \& Fig. 2e) total cholesterol (18 studies with 22 effect sizes) (WMD: -10.88; 95\% CI -18.60, 3.17) (Table 2 \& Fig. 2f), LDL-cholesterol (15 studies with 19 effect sizes) (WMD: -8.47\% CI: - 16.59, - 0.36)
(Table 2 \& Fig. 2j) and total cholesterol/HDL-cholesterol (3 studies) (WMD: -0.26; 95\% CI: - 0.41, - 0.10) (Table 2 \& Fig. 2k) was found following the consumption of whey protein. Whey protein did not have any significant impact on HDLcholesterol (17 studies with 21 effect sizes) (WMD: -0.13; 95\% CI: $-1.74,1.48$ ) (Table 2 \& Fig. 2h). The quality of evidence was low for triglycerides, total and LDL-cholesterol in GRADE system. While HDL-cholesterol had a very low evidence quality of evidence. For total cholesterol/HDLcholesterol the quality of evidence was high (Supplemental file- Table 3). After adjustment, PI showed that results remained significant for triglycerides (95\%PI: - 27.41, 7.70 ), total cholesterol (95\%PI: - 20.32, - 5.09), LDL- 
Table 3 Subgroup analyses for the effects of whey protein intake on glycemic control and serum lipoproteins

\begin{tabular}{|c|c|c|c|c|c|c|c|}
\hline \multicolumn{2}{|c|}{ Variables } & \multirow{2}{*}{$\begin{array}{l}\text { Subgroups } \\
\text { Adult }\end{array}$} & \multirow{2}{*}{$\begin{array}{l}\begin{array}{l}\text { Number of effect } \\
\text { sizes }\end{array} \\
12\end{array}$} & \multirow{2}{*}{$\begin{array}{l}\begin{array}{l}\text { Pooled } \\
\text { WMD }\end{array} \\
-0.30 \\
\end{array}$} & \multirow{2}{*}{$\begin{array}{l}95 \% \mathrm{Cl} \\
-1.29,0.69\end{array}$} & \multirow{2}{*}{$\begin{array}{l}\mathbf{I}^{2} \\
\text { (\%) }\end{array}$} & \multirow{2}{*}{$\begin{array}{l}\begin{array}{l}\text { Between- } \\
\text { study } \\
I^{2}(\%)\end{array} \\
<0.001\end{array}$} \\
\hline FPG & Participants' age & & & & & & \\
\hline & & Adult+Elderly & 8 & -3.79 & $-4.65,-2.93$ & 86.0 & \\
\hline & Participants' health & Healthy & 12 & -2.12 & $-2.87,-1.37$ & 90.9 & 0.40 \\
\hline & & Chronic disease & 8 & -2.76 & $-4.05,-1.47$ & 89.8 & \\
\hline & Intervention type & Isolated & 6 & 0.35 & $-1.57,2.28$ & 76.8 & $<0.01$ \\
\hline & & Whey proteins & 14 & -2.72 & $-3.43,-2.01$ & 92.0 & \\
\hline & Study duration & $<12$ week & 9 & -1.62 & $-2.64,-0.60$ & 90.6 & 0.09 \\
\hline & & $\geq 12$ week & 11 & -2.74 & $-3.58,-1.89$ & 90.3 & \\
\hline & Sample size & $\mathrm{n}<50$ & 13 & -2.05 & $-2.89,-1.22$ & 91.7 & 0.38 \\
\hline & & $n \geq 50$ & 7 & -2.64 & $-3.67,-1.61$ & 86.5 & \\
\hline & Type of control & Placebo product & 3 & -1.22 & $-3.33,1.43$ & 00.0 & $<0.001$ \\
\hline & & $\begin{array}{l}\text { Carbohydrate } \\
\text { supplementation }\end{array}$ & 13 & -0.73 & $-1.61,0.15$ & 88.9 & \\
\hline & & Non-intervention & 4 & -4.54 & $-5.56,-3.51$ & 92.8 & \\
\hline \multirow[t]{8}{*}{$\mathrm{HbA1C}$} & Participants' age & Adult & 3 & -0.15 & $-0.21,-0.08$ & 96.2 & 0.16 \\
\hline & & Adult+Elderly & 3 & -0.09 & $-0.14,-0.04$ & 36.6 & \\
\hline & Participants' health & Healthy & 3 & -0.08 & $-0.12,-0.03$ & 00.0 & 0.02 \\
\hline & condition & Chronic disease & 3 & -0.17 & $-0.23,-0.10$ & 96.1 & \\
\hline & Study duration & $<12$ week & 3 & -0.06 & $-0.10,-0.01$ & 49.4 & $<0.001$ \\
\hline & & $\geq 12$ week & 3 & -0.33 & $-0.42,-0.24$ & 91.2 & \\
\hline & Sample size & $\mathrm{n}<50$ & 3 & -0.11 & $-0.16,-0.06$ & 94.7 & 0.91 \\
\hline & & $n \geq 50$ & 3 & -0.11 & $-0.17,-0.05$ & 20.1 & \\
\hline \multirow[t]{13}{*}{ Insulin } & Participants' age & Adult & 9 & -1.43 & $-2.21,0.65$ & 48.0 & 0.01 \\
\hline & & Adult+Elderly & 5 & -0.34 & $-0.74,0.07$ & 7.09 & \\
\hline & Participants' health & Healthy & 10 & -0.39 & $-0.078,-0.00$ & 63.6 & 0.01 \\
\hline & condition & Chronic disease & 4 & -1.67 & $-2.63,-0.70$ & 33.4 & \\
\hline & Intervention type & Isolated & 4 & -1.15 & $-2.10,-0.20$ & 67.2 & 0.09 \\
\hline & & Whey proteins & 10 & -0.42 & $-0.81,-0.03$ & 62.9 & \\
\hline & Study duration & $<12$ week & 7 & -0.49 & $-0.95,-0.03$ & 68.5 & 0.59 \\
\hline & & $\geq 12$ week & 7 & -0.69 & $-1.27,-0.11$ & 61.7 & \\
\hline & Sample size & $\mathrm{n}<50$ & 7 & -0.60 & $-1.17,-0.02$ & 69.8 & 0.89 \\
\hline & & $n \geq 50$ & 7 & -0.55 & $-1.01,-0.09$ & 60.3 & \\
\hline & Type of control & Placebo product & 2 & -3.30 & $-5.18,1.42$ & 00.0 & 0.01 \\
\hline & & $\begin{array}{l}\text { Carbohydrate } \\
\text { supplementation }\end{array}$ & 9 & -0.64 & $-1.16,-0.11$ & 56.8 & \\
\hline & & Non-intervention & 5 & -0.30 & $-0.81,0.21$ & 70.6 & \\
\hline \multirow{7}{*}{$\begin{array}{l}\text { HOMA- } \\
\text { IR }\end{array}$} & Participants' age & Adult & 9 & -0.25 & $-0.38,-0.11$ & 64.9 & 0.02 \\
\hline & & Adult+Elderly & 4 & -0.07 & $-0.13,-0.01$ & 64.8 & \\
\hline & Participants' health & Healthy & 8 & -0.07 & $-0.13,-0.01$ & 59.6 & $<0.001$ \\
\hline & & Chronic disease & 5 & -0.48 & $-0.70,-0.26$ & 42.2 & \\
\hline & Intervention type & Isolated & 4 & -0.20 & $-0.33,-0.06$ & 72.8 & 0.04 \\
\hline & & Whey proteins & 9 & -0.07 & $-0.13,-0.01$ & 64.1 & \\
\hline & Study duration & $<12$ week & 7 & -0.04 & $-0.14,0.06$ & 80.2 & $<0.18$ \\
\hline
\end{tabular}


Table 3 Subgroup analyses for the effects of whey protein intake on glycemic control and serum lipoproteins (Continued)

\begin{tabular}{|c|c|c|c|c|c|c|c|}
\hline \multicolumn{2}{|c|}{ Variables } & \multirow{2}{*}{$\begin{array}{l}\text { Subgroups } \\
\geq 12 \text { week }\end{array}$} & \multirow{2}{*}{$\begin{array}{l}\text { Number of effect } \\
\text { sizes }\end{array}$} & \multirow{2}{*}{$\begin{array}{l}\begin{array}{l}\text { Pooled } \\
\text { WMD }\end{array} \\
-0.12 \\
\end{array}$} & \multirow{2}{*}{$\begin{array}{l}95 \% \mathrm{Cl} \\
-0.19,-0.06\end{array}$} & \multirow{2}{*}{$\begin{array}{l}I^{2} \\
\text { (\%) }\end{array}$} & \multirow[t]{2}{*}{$\begin{array}{l}\text { Between- } \\
\text { study } \\
I^{2}(\%)\end{array}$} \\
\hline & & & & & & & \\
\hline & Sample size & $\mathrm{n}<50$ & 6 & -0.11 & $-0.19,-0.04$ & 74.2 & 0.47 \\
\hline & & $n \geq 50$ & 7 & -0.07 & $-0.16,0.01$ & 64.1 & \\
\hline & Type of control & Placebo product & 2 & -0.86 & $-1.43,-0.29$ & 00.0 & $<0.01$ \\
\hline & & $\begin{array}{l}\text { Carbohydrate } \\
\text { supplementation }\end{array}$ & 8 & -0.22 & $-0.35,-0.10$ & 61.6 & \\
\hline & & Non-intervention & 3 & -0.06 & $-0.12,0.01$ & 66.1 & \\
\hline \multirow[t]{13}{*}{$\mathrm{TC}$} & Participants' age & Adult & 12 & -12.86 & $-16.11,-9.61$ & 81.7 & 0.06 \\
\hline & & Adult+Elderly & 10 & -9.07 & $-11.39,-6.74$ & 96.1 & \\
\hline & Participants' health & Healthy & 15 & -8.75 & $-10.87,-6.63$ & 94.3 & 0.001 \\
\hline & & Chronic disease & 7 & -16.40 & $\begin{array}{l}-20.53,- \\
12.27\end{array}$ & 84.7 & \\
\hline & Intervention type & Isolated & 7 & -9.67 & $-12.52,-6.82$ & 95.6 & 0.10 \\
\hline & & Whey proteins & 15 & -11.77 & $-14.43,-9.11$ & 99.5 & \\
\hline & Study duration & $<12$ week & 10 & -15.83 & $\begin{array}{l}-18.33,- \\
13.34\end{array}$ & 96.1 & $<0.001$ \\
\hline & & $\geq 12$ week & 12 & -3.01 & $-5.90,-0.12$ & 40.6 & \\
\hline & Sample size & $\mathrm{n}<50$ & 14 & -11.24 & $-13.32,-9.15$ & 95.3 & 0.04 \\
\hline & & $n \geq 50$ & 8 & -6.21 & $-10.71,-1.71$ & 44.1 & \\
\hline & Type of control & Placebo product & 2 & -1.99 & $-10.44,6.47$ & 00.0 & 0.07 \\
\hline & & $\begin{array}{l}\text { Carbohydrate } \\
\text { supplementation }\end{array}$ & 16 & -11.49 & $-13.76,-9.22$ & 91.0 & \\
\hline & & Non-intervention & 4 & -8.92 & $-12.63,-5.20$ & 97.5 & \\
\hline \multirow[t]{13}{*}{ TG } & Participants' age & Adult & 11 & -6.78 & $-10.71,-2.85$ & 76.4 & $<0.001$ \\
\hline & & Adult+Elderly & 11 & -21.43 & $\begin{array}{l}-24.28 \\
-18.58\end{array}$ & 94.2 & \\
\hline & $\begin{array}{l}\text { Participants' health } \\
\text { condition }\end{array}$ & Healthy & 15 & -15.58 & $\begin{array}{l}-17.99,- \\
13.16\end{array}$ & 94.1 & 0.02 \\
\hline & & Chronic disease & 7 & -25.04 & $-32.96,-17.11$ & 1.0 & \\
\hline & Intervention type & Isolated & 7 & -13.90 & $-16.94,10.87$ & 97.0 & 0.04 \\
\hline & & Whey proteins & 15 & -19.86 & $\begin{array}{l}-23.47,- \\
16.25\end{array}$ & 69.8 & \\
\hline & Study duration & $<12$ week & 9 & -15.63 & $\begin{array}{l}-18.60,- \\
12.66\end{array}$ & 96.2 & 0.43 \\
\hline & & $\geq 12$ week & 13 & -17.52 & $\begin{array}{l}-21.19,- \\
13.85\end{array}$ & 66.3 & \\
\hline & Sample size & $\mathrm{n}<50$ & 13 & -17.05 & $\begin{array}{l}-19.50,- \\
14.59\end{array}$ & 94.9 & 0.11 \\
\hline & & $n \geq 50$ & 9 & -11.33 & $-18.06,-4.59$ & 36.9 & \\
\hline & Type of control & Placebo product & 2 & -25.36 & $-41.44,-0.29$ & 00.0 & 0.20 \\
\hline & & $\begin{array}{l}\text { Carbohydrate } \\
\text { supplementation }\end{array}$ & 16 & -15.14 & $\begin{array}{l}-17.90,- \\
12.38\end{array}$ & 93.9 & \\
\hline & & Non-intervention & 4 & -18.81 & $\begin{array}{l}-23.18,- \\
14.44\end{array}$ & 00.0 & \\
\hline \multirow[t]{3}{*}{ LDL } & Participants' age & Adult & 9 & -1.73 & $-5.32,1.87$ & 47.1 & 0.001 \\
\hline & & Adult+ Elderly & 10 & -8.9 & $-10.98,-6.81$ & 96.9 & \\
\hline & Participants' health & Healthy & 14 & -8.31 & $-10.25,-6.36$ & 95.7 & 0.001 \\
\hline
\end{tabular}


Table 3 Subgroup analyses for the effects of whey protein intake on glycemic control and serum lipoproteins (Continued)

\begin{tabular}{|c|c|c|c|c|c|c|c|}
\hline \multicolumn{2}{|c|}{ Variables } & \multirow{2}{*}{$\begin{array}{l}\text { Subgroups } \\
\text { Chronic disease }\end{array}$} & \multirow{2}{*}{$\begin{array}{l}\text { Number of effect } \\
\text { sizes }\end{array}$} & \multirow{2}{*}{\begin{tabular}{|l}
$\begin{array}{l}\text { Pooled } \\
\text { WMD }\end{array}$ \\
0.45
\end{tabular}} & \multirow{2}{*}{$\begin{array}{l}95 \% \mathrm{Cl} \\
-4.39,5.29\end{array}$} & \multirow{2}{*}{$\begin{array}{l}I^{2} \\
(\%)\end{array}$} & \multirow[t]{2}{*}{$\begin{array}{l}\text { Between- } \\
\text { study } \\
I^{2}(\%)\end{array}$} \\
\hline & condition & & & & & & \\
\hline & \multirow[t]{2}{*}{ Intervention type } & Isolated & 5 & -10.49 & $-13.75,-7.22$ & 88.7 & $<0.01$ \\
\hline & & Whey proteins & 14 & -6.41 & $-8.67,-4.15$ & 96.1 & \\
\hline & \multirow[t]{2}{*}{ Study duration } & $<12$ week & 8 & -18.51 & $\begin{array}{l}-21.39,- \\
15.62\end{array}$ & 96.1 & $<0.001$ \\
\hline & & $\geq 12$ week & 11 & 0.22 & $-2.09,2.52$ & 73.7 & \\
\hline & \multirow[t]{2}{*}{ Sample size } & $\mathrm{n}<50$ & 11 & -5.88 & $-7.98,-3.79$ & 94.9 & 0.02 \\
\hline & & $n \geq 50$ & 8 & -10.56 & $-14.11,-7.02$ & 94.1 & \\
\hline & \multirow[t]{3}{*}{ Type of control } & Placebo product & 2 & 4.36 & $-2.84,11.56$ & 54.4 & $<0.01$ \\
\hline & & $\begin{array}{l}\text { Carbohydrate } \\
\text { supplementation }\end{array}$ & 14 & -7.75 & $-10.28,5.23$ & 81.3 & \\
\hline & & Non-intervention & 3 & -7.98 & $-10.74,-5.22$ & 99.2 & \\
\hline \multirow[t]{13}{*}{$\mathrm{HDL}$} & \multirow[t]{2}{*}{ Participants' age } & Adult & 11 & -1.65 & $-2.41,-0.89$ & 34.4 & $<0.001$ \\
\hline & & Adult+ Elderly & 10 & 1.40 & $1.10,1.71$ & 94.3 & \\
\hline & \multirow{2}{*}{$\begin{array}{l}\text { Participants' health } \\
\text { condition }\end{array}$} & Healthy & 14 & 1.48 & $1.17,1.79$ & 94.5 & $<0.001$ \\
\hline & & Chronic disease & 7 & -1.94 & $-2.68,-1.20$ & 87.1 & \\
\hline & \multirow[t]{2}{*}{ Intervention type } & Isolated & 6 & 1.57 & $1.25,1.89$ & 97.7 & $<0.001$ \\
\hline & & Whey proteins & 15 & -1.15 & $-1.79,-0.51$ & 83.6 & \\
\hline & \multirow[t]{2}{*}{ Study duration } & $<12$ week & 9 & 1.05 & $0.76,1.35$ & 97.6 & 0.13 \\
\hline & & $\geq 12$ week & 12 & 0.32 & $-0.58,1.22$ & 34.9 & \\
\hline & \multirow[t]{2}{*}{ Sample size } & $\mathrm{n}<50$ & 13 & 1.15 & $0.85,1.44$ & 96.3 & $<0.001$ \\
\hline & & $n \geq 50$ & 8 & -0.66 & $-1.59,0.28$ & 56.0 & \\
\hline & \multirow[t]{3}{*}{ Type of control } & Placebo product & 2 & 1.61 & $-0.09,3.32$ & 78.0 & 0.15 \\
\hline & & $\begin{array}{l}\text { Carbohydrate } \\
\text { supplementation }\end{array}$ & 16 & 1.04 & $0.74,1.33$ & 95.5 & \\
\hline & & Non-intervention & 3 & 0.03 & $-1.03,1.09$ & 70.6 & \\
\hline
\end{tabular}

HOMA IR homeostasis model assessment of insulin resistance, HbA1c glycated hemoglobin, TG triglyceride, TC total cholesterol, HDL-C HDL-cholesterol, LDL-C LDL-cholesterol

cholesterol (95\%PI: - 15.96, - 0.51), and total cholesterol/ HDL-cholesterol (95\%PI: $-0.69,-0.07$ ), but this finding were insignificant for HDL-cholesterol (95\%PI: - 1.90, 1.00).

Whey protein reduced triglycerides concentrations in all subgroups. In a subgroup analysis of total cholesterol, a significant change was seen in all subgroups except in studies which used placebo (WMD: -1.99; 95\% CI: $10.44,6.47$ ) (Table 3). Whey protein intake did not have an effect on LDL-cholesterol levels in studies which were performed on adults (WMD: -1.73; 95\% CI: - 5.32, 1.87), in studies done on patients with chronic diseases (WMD: 0.45; 95\% CI -4.39, 5.29), and in studies with duration $\geq 12$ weeks (WMD: 0.22; 95\% CI: $-2.09,2.52$ ) or those which used placebo (WMD: 4.36; 95\% CI: $2.84,11.56)$. Whey protein did not have an effect on HDL-cholesterol levels in some subgroups, including studies with duration $\geq 12$ weeks (WMD: 0.32; 95\% CI: $0.58,1.22$ ) and sample size $\geq 50$ (WMD: -0.66 ; $95 \%$ CI: -
$1.59,0.28)$ and in studies which used placebo (WMD: 1.61; 95\% CI: $-0.09,3.32$ ) or non-intervention controls (WMD: 0.03; 95\% CI: - 1.03, 1.09).

\section{Publication bias and sensitivity analysis}

Publication bias was investigated for outcomes with at least 10 related studies, including FBS, TC, TG, LDL, and HDL. Visual inspection of funnel plots showed no significant publication bias for the included studies (Supplemental file- Fig. 1A-J). This finding was also confirmed by the Eggers' regression test (For FBS: $P=0.05$; for TC: $P=0.74$; for TG: $P=0.81$; for LDL: 0.44 ; for HDL: 0.37$)$. Sensitivity analysis also showed that no specific study had great influence on the overall findings of the study (Supplemental file- Fig. 2A-E).

\section{Meta-regression}

Dose-response analysis for the influence of study duration on the association between whey protein 
supplementation and outcomes of interest was measured using meta-regression. This analysis did not show any significant dose-response association between study duration and changes in FPG $(P=0.79)$, HOMA-IR $(P=$ $0.36)$, HbA1C $(P=0.49)$, total cholesterol $(P=0.43)$, triglycerides $(P=0.22)$, LDL-cholesterol $(P=0.27)$, and HDL-cholesterol $(P=0.62)$ concentrations. However, a marginally significant inverse association was found between study duration and changes in insulin concentrations $(P=0.05)$. This means that reduction in insulin concentration following whey protein supplementation was more considerable in studies with longer intervention period.

\section{Discussion}

For the first time, this meta-analysis analyzed whey protein effects on serum lipoproteins and parameters of glucose homeostasis in patients with MetS and related disorders. It indicated that whey protein might improve insulin, HOMA-IR, HbA1c triglycerides, total cholesterol, LDL-cholesterol and total cholesterol/HDL-cholesterol ratio in MetS and related disorders, but it had no effects on HDL-cholesterol and FPG levels.

\section{Whey protein and glucose metabolism}

This meta-analysis suggested that whey protein significantly decreased the levels of insulin as well as HOMAIR and HbA1c, but did not have any effect on FPG levels. In the present study, subgroup analyses based on sample size, duration and health condition showed a significant reduction in FPG levels. However, after PI estimation, results were insignificant for all parameters of glycemic control which maybe reflective of the variation in settings and treatment effects. Previously, some epidemiological studies have demonstrated that consumption of milk and/or dairy products was correlated with a lower risk of metabolic changes and CVD. In particular, whey protein intake seems to improve metabolic parameters due to bioactive substances, including immunoglobulins, glutamine, lactoferrin and lactalbumin. It is also an excellent source of BCAAs. However, results of different studies are conflicting. Whey protein supplementation has been suggested for both prevention and treatment of obesity and diabetes in humans and in animal models [42]. One of the reasons could be the reduction of the long and short term appetite [43]. In a study by Rigamonti et al. [44], taking whey proteins improved glucometabolic homeostasis in young obese women. Two recent meta-analyses including studies on overweight and obese participants, have indicated that whey protein administration might improve FPG levels [11, 45]. Taking whey proteins during 12 weeks in overweight and obese individuals significantly improved their insulin levels and decreased total cholesterol and LDL-cholesterol levels
[10]. However, the consumption of $125 \mathrm{~mL} /$ day of a milk drink supplemented with whey peptides for 12 weeks by mildly hypertensive subjects did not improve metabolic parameters such as FPG, insulin and serum lipids [22]. In subjects with PCOs, a hypocaloric diet plus whey protein did not affect glycemic control [24]. Low fat high-casein or whey protein rich weight maintenance diets had not adverse effects on metabolic parameters and markers of cardiovascular risk in moderately obese patients without metabolic or cardiovascular complications while reduced their weight [26]. Whey protein may be involved in decreasing postprandial hyperglycemia and could improve the insulin response by different mechanisms. After its digestion, a rapid increase in amino acids (BCAAs, in particular) results in increased insulin release which probably improves postprandial hyperglycemia. Bioactive peptides also activate the release of incretin hormones including GIP and GLP-1 which have an important role in improvement of insulin resistance. On the other hand, peptides from hydrolyzation of whey inhibit dipeptidyl peptidaseIV and inhibit degradation of GIP and GLP-1 [46]. Based on all these results as well as this study, short-term insulinotrophic effect of whey proteins may be a beneficial in the management of MetS and/or T2DM.

\section{Whey protein and serum lipoproteins}

This meta-analysis showed that whey protein decreased triglycerides, total cholesterol, LDL-cholesterol and total cholesterol/HDL-cholesterol ratio in patients with MetS and its components, but did not have any effect on HDL-cholesterol levels. In the present study, the reduction of triglycerides was significant in all subgroups and total cholesterol also significantly reduced in the most subgroups. HDL-cholesterol levels also were increased in some subgroup analyses such as studies used carbohydrate supplementation as control which may represent that the using of certain control may affect the findings of studies regarding the efficacy of whey protein supplement on HDL-cholesretol levels. Increase in HDLcholesterol levels was significant in studies conducted among adult and elderly populations, individuals without chronic diseases and studies with less than 12 weeks' duration or with less than 50 participants. PI estimation, did not affect the significance of results for lipid profiles. Recently, a meta-analysis by Badely et al. [45] has been done to explore the effects of whey protein supplementation in overweight and obese subjects. The results indicated that whey protein supplementation when compared with different kind of controls caused a significant reduction in triglycerides and HDL-cholesterol in this population. However, a significant heterogeneity has been reported for these parameters. In another meta-analysis by Zhang et al. [47], whey protein intake also significantly decreased triglycerides levels and had 
no effects on total cholesterol, LDL- and HDLcholesterol but the subgroup analyses showed that significant reduction of triglycerides disappeared in several cases including lower dosage of whey protein, low BMI groups of participants, exercise performing and energy restriction during the trial. In a study by Fekete et al. [31], the consumption of unhydrolyzed milk proteins ( $56 \mathrm{~g} /$ day) during 8 weeks in subjects with prehypertension and mild HTN decreased serum triglycerides, and improved biomarkers of endothelial function and vascular reactivity. Moderate-high doses of whey protein during 16 weeks significantly reduced total cholesterol/ HDL-cholesterol ratio in obese men [37]. Fortified yogurt with whey protein during 10 -week significantly reduced triglycerides levels in patients with MetS [9]. As mentioned before, supplementation with whey proteins during 12 weeks in overweight and obese subjects was associated with a significant decrease in total cholesterol and LDL-cholesterol [10]. In another study, a 12-week supplementation with whey protein in subjects with prehypertension and mildly hypertensive patients did not have any significant effect on serum lipoproteins [40]. Calcium intake from dairy products has been correlated with calcium-fatty acid soap production in the gut, which in turn results in decreased fat absorption [48] Therefore, calcium intake from whey protein may be responsible for the lipid-lowering effects of this protein. Different proteins from different sources and qualities could cause different metabolic effects [49, 50]. Whey protein intake might have effects on lipid metabolism by inhibition of cholesterol absorption in the intestine mediated by its functional components like beta-lactoglobulin and sphingolipids. In addition, other lipid lowering mechanisms like stimulation of lipoprotein lipase, and downregulation of gene expression important for cholesterol absorption and fatty acid transport have been associated to BCAAs content of whey protein [51-54].

\section{Study strengths and limitations}

This study is a comprehensive systematic review and meta-analysis of studies about the effect of whey protein supplementation on serum levels of several metabolic parameters. Previous meta-analyses focused on the metabolic effects of whey protein in obese and overweight individuals, while this meta-analysis has been done on studies in patients with MetS and related disorders. However, this study has some limitations. First, whey protein was used in different dosages in the included studies. Moreover, study duration and control group were varied between included studies. We tried to minimize these discrepancies by different subgroup analyses. Intervention period was limited in all the included studies. Therefore, RCTs with longer duration are needed to determine clearly the effects of whey protein supplementation on metabolic parameters in moderate to long-term interventions. The limited sample size of included studies was another limitation. In addition, most included studies were done in Western countries and only limited data are available from Asian and Australian populations. In addition, included studies suffer from different sources of bias in some aspects and this should be taken into consideration. Also, due to various regimens, doses, duration, center settings, populations and sample size the results of present study should be interpreted with cautious. Therefore, further large-scale studies on different populations are required to provide some clear answers concerning.

\section{Conclusions}

This meta-analysis indicated potential effects of whey protein on improving HbA1c, insulin, HOMA-IR, triglycerides, total cholesterol, LDL-cholesterol and total/ HDL-cholesterol ratio in patients with MetS and related disorders, but it did not show any effect on HDLcholesterol, and FPG levels. In the present study, the significance of findings for parameters of glycemic status were disappeared after PI estimation, which may be due to the heterogeneity. Therefore, the efficacy of whey protein supplementation on glycemic control should be identified in future studies. In order to overcome different sources of bias future RCTs need to be designed with appropriate blinding, allocation concealment and data report to overcome different sources of bias.

\section{Supplementary information}

Supplementary information accompanies this paper at https://doi.org/10. 1186/s12944-020-01384-7.

Additional file 1: Table 1. Search strategies and the number of publications in each electronic database. Table 2. Cochrane quality assessment of the included studies. Table $\mathbf{3}$. GRADE summary of findings.

Additional file 2: Fig. 1A-J. Funnel plots for A) FPG, B) insulin, C) HOMA-IR, D) triglycerides, E) total cholesterol, F) LDL-cholesterol and J) HDL-cholesterol. Fig. 2A-E. Funnel plots for A) FPG, B) triglycerides, C) total cholesterol, D) LDL-cholesterol and E) HDL-cholesterol.

\section{Abbreviations}

HOMA IR: Homeostasis model assessment of insulin resistance; HbA1c: Glycated hemoglobin; TG: Triglycerides; TC: Total cholesterol; HDLC: HDL-cholesterol; LDL-C: LDL-cholesterol

\section{Acknowledgements}

Not applicable.

\section{Authors' contributions}

ZA contributed in conception, design, statistical analysis and drafting of the manuscript. EA, AM, HM, MAM contributed in data collection and ZR contributed in manuscript drafting. All authors approved the final version for submission. ZA supervised the study.

Funding

Not applicable. 


\section{Availability of data and materials}

The primary data for this study is available from the authors on direct request.

\section{Ethics approval and consent to participate} Not applicable.

\section{Consent for publication}

Not applicable.

\section{Competing interests}

The authors declare no conflict of interest.

\begin{abstract}
Author details
'Research Center for Biochemistry and Nutrition in Metabolic Diseases, Institute for Basic Sciences, Kashan University of Medical Sciences, Kashan, Iran. ${ }^{2}$ Students' Scientific Research Center, Tehran University of Medical Sciences, Tehran, Iran. ${ }^{3}$ Department of Community Nutrition, School of Nutritional Sciences and Dietetics, Tehran University of Medical Sciences, Tehran, Iran. ${ }^{4}$ Department of Internal Medicine, University Hospital Centre Zagreb, School of Medicine, University of Zagreb, Zagreb, Croatia. ${ }^{5}$ Department of Epidemiology and Biostatistics, School of Public Health, Tehran University of Medical Sciences, Tehran, Iran.
\end{abstract}

Received: 6 February 2020 Accepted: 6 September 2020 Published online: 21 September 2020

\section{References}

1. Grundy SM, Brewer HB Jr, Cleeman JI, Smith SC Jr, Lenfant C. Definition of metabolic syndrome: report of the National Heart, Lung, and Blood Institute/American Heart Association conference on scientific issues related to definition. Circulation. 2004;109:433-8.

2. Balkau B, Vernay M, Mhamdi L, Novak M, Arondel D, Vol S, et al. The incidence and persistence of the NCEP (National Cholesterol Education Program) metabolic syndrome. French DESIR study Diabetes Metab. 2003;29:526-32.

3. Golden SH, Robinson KA, Saldanha I, Anton B, Ladenson PW. Clinical review: prevalence and incidence of endocrine and metabolic disorders in the United States: a comprehensive review. J Clin Endocrinol Metab. 2009;94:1853-78.

4. Beydoun MA, Gary TL, Caballero BH, Lawrence RS, Cheskin LJ, Wang Y. Ethnic differences in dairy and related nutrient consumption among US adults and their association with obesity, central obesity, and the metabolic syndrome. Am J Clin Nutr. 2008;87:1914-25.

5. Pereira MA, Jacobs DR Jr, Van Horn L, Slattery ML, Kartashov Al, Ludwig DS. Dairy consumption, obesity, and the insulin resistance syndrome in young adults: the CARDIA study. Jama. 2002;287:2081-9.

6. Huth PJ, DiRienzo DB, Miller GD. Major scientific advances with dairy foods in nutrition and health. J Dairy Sci. 2006;89:1207-21.

7. Sousa GT, Lira FS, Rosa JC, de Oliveira EP, Oyama LM, Santos RV, et al. Dietary whey protein lessens several risk factors for metabolic diseases: a review. Lipids Health Dis. 2012;11:67.

8. Cicero AFG, Fogacci F, Colletti A. Potential role of bioactive peptides in prevention and treatment of chronic diseases: a narrative review. $\mathrm{Br} J$ Pharmacol. 2017;174:1378-94.

9. Mohammadi-Sartang M, Bellissimo N, Totosy de Zepetnek JO, Brett NR, Mazloomi SM, Fararouie M, et al. The effect of daily fortified yogurt consumption on weight loss in adults with metabolic syndrome: A 10-week randomized controlled trial. Nutr Metab Cardiovasc Dis. 2018;28:565-74.

10. Pal S, Ellis $V$, Dhaliwal S. Effects of whey protein isolate on body composition, lipids, insulin and glucose in overweight and obese individuals. Br J Nutr. 2010;104:716-23.

11. Wirunsawanya K, Upala S, Jaruvongvanich V, Sanguankeo A. Whey protein supplementation improves body composition and cardiovascular risk factors in overweight and obese patients: a systematic review and meta-analysis. J Am Coll Nutr. 2018;37:60-70.

12. Alberti KG, Eckel RH, Grundy SM, Zimmet PZ, Cleeman II, Donato KA, et al. Harmonizing the metabolic syndrome: a joint interim statement of the international diabetes federation task force on epidemiology and prevention National Heart, Lung, and Blood Institute; American Heart Association; world heart federation; international atherosclerosis society; and International Association for the Study of obesity. Circulation. 2009;120:1640-5.
13. Higgins JP, Eldridge S, Li T. Including variants on randomized trials. Cochrane handbook for systematic reviews of interventions. 2019;13:569-93.

14. Wan X, Wang W, Liu J, Tong T. Estimating the sample mean and standard deviation from the sample size, median, range and/or interquartile range. BMC Med Res Methodol. 2014;14:135.

15. Higgins JP, Li T, Deeks JJ. Choosing effect measures and computing estimates of effect. Cochrane Handbook for Systematic Reviews of Interventions. 2019;6:143-76. https://doi.org/10.1002/9781119536604.ch6.

16. UnitsLab.com (database on the Internet).Cited 2020.Available from: http:// unitslab.com/.

17. Guasch-Ferré M, Satija A, Blondin SA, Janiszewski M, Emlen E, O'Connor LE, et al. Meta-analysis of randomized controlled trials of red meat consumption in comparison with various comparison diets on cardiovascular risk factors. Circulation. 2019;139:1828-45.

18. Overvad K, Diamant B, Holm L, Holmer G, Mortensen SA, Stender S. Coenzyme Q10 in health and disease. Eur J Clin Nutr. 1999:53:764-70.

19. Higgins JP, Thompson SG, Deeks JJ, Altman DG. Measuring inconsistency in meta-analyses. BMJ. 2003;327:557-60.

20. IntHout J, loannidis JP, Rovers MM, Goeman JJ. Plea for routinely presenting prediction intervals in meta-analysis. BMJ Open. 2016;6:e010247.

21. Egger M, Davey Smith G, Schneider M, Minder C. Bias in meta-analysis detected by a simple, graphical test. Bmj. 1997;315:629-34.

22. Lee YM, Skurk T, Hennig M, Hauner H. Effect of a milk drink supplemented with whey peptides on blood pressure in patients with mild hypertension. Eur J Nutr. 2007:46:21-7.

23. Frestedt JL, Zenk JL, Kuskowski MA, Ward LS, Bastian ED. A whey-protein supplement increases fat loss and spares lean muscle in obese subjects: a randomized human clinical study. Nutr Metabol. 2008:5:8.

24. Kasim-Karakas SE, Almario RU, Cunningham W. Effects of protein versus simple sugar intake on weight loss in polycystic ovary syndrome (according to the National Institutes of Health criteria). Fertil Steril. 2009;92:262-70.

25. Denysschen CA, Burton HW, Horvath PJ, Leddy JJ, Browne RW. Resistance training with soy vs whey protein supplements in hyperlipidemic males. J Int Soc Sports Nutr. 2009;6:8.

26. Claessens M, van Baak MA, Monsheimer S, Saris WH. The effect of a low-fat, high-protein or high-carbohydrate ad libitum diet on weight loss maintenance and metabolic risk factors. Int J Obesity (2005). 2009;33:296-304.

27. Sheikholeslami Vatani D, Ahmadi Kani Golzar F. Changes in antioxidant status and cardiovascular risk factors of overweight young men after six weeks supplementation of whey protein isolate and resistance training. Appetite. 2012;59:673-8.

28. Petyaev IM, Dovgalevsky PY, Klochkov VA, Chalyk NE, Kyle N. Whey protein lycosome formulation improves vascular functions and plasma lipids with reduction of markers of inflammation and oxidative stress in prehypertension. TheScientificWorld Journal. 2012;2012:269476.

29. Tovar J, Nilsson A, Johansson M, Ekesbo R, Aberg AM, Johansson U, et al. A diet based on multiple functional concepts improves cardiometabolic risk parameters in healthy subjects. Nutr Metabol. 2012;9:29.

30. Ormsbee MJ, Kinsey AW, Eddy WR, Madzima TA, Arciero PJ, Figueroa A, et al. The influence of nighttime feeding of carbohydrate or protein combined with exercise training on appetite and cardiometabolic risk in young obese women. Appl Physiol Nutr Metabol = Physiologie appliquee, nutrition et metabolisme. 2015:40:37-45.

31. Fekete AA, Giromini C, Chatzidiakou Y, Givens DI, Lovegrove JA. Whey protein lowers blood pressure and improves endothelial function and lipid biomarkers in adults with prehypertension and mild hypertension: results from the chronic Whey2Go randomized controlled trial. Am J Clin Nutr. 2016;104:1534-44.

32. Tovar J, Johansson M, Björck I. A multifunctional diet improves cardiometabolic-related biomarkers independently of weight changes: an 8week randomized controlled intervention in healthy overweight and obese subjects. Eur J Nutr. 2016;55:2295-306.

33. Jakubowicz D, Wainstein J, Landau Z, Ahren B, Barnea M, Bar-Dayan Y, et al. Highenergy breakfast based on whey protein reduces body weight, postprandial glycemia and HbA1C in type 2 diabetes. J Nutr Biochem. 2017;49:1-7.

34. Lopes Gomes D, Moehlecke M, Lopes da Silva FB, Dutra ES, D'Agord Schaan B, Baiocchi de Carvalho KM. Whey Protein Supplementation Enhances Body Fat and Weight Loss in Women Long After Bariatric Surgery: a Randomized Controlled Trial Obesity surgery. Obes Surg. 2017;27(2):424-31.

35. Kjølbæk L, Sørensen LB, Søndertoft NB, Rasmussen CK, Lorenzen JK, Serena A, et al. Protein supplements after weight loss do not improve weight maintenance compared with recommended dietary protein intake despite 
beneficial effects on appetite sensation and energy expenditure: a randomized, controlled, double-blinded trial. Am J Clin Nutr. 2017;106:684-97.

36. Watson LE, Phillips LK, Wu T, Bound MJ, Checklin HL, Grivell J, et al. A whey/ guar "preload" improves postprandial glycaemia and glycated haemoglobin levels in type 2 diabetes: A 12-week, single-blind, randomized, placebocontrolled trial. Diabetes Obes Metab. 2019;21(4):930-8.

37. Kemmler W, Kohl M, Freiberger E, Sieber C, von Stengel S. Effect of wholebody electromyostimulation and / or protein supplementation on obesity and cardiometabolic risk in older men with sarcopenic obesity: the randomized controlled FranSO trial. BMC Geriatr. 2018;18:70.

38. Gaffney KA, Lucero A, Stoner L, Faulkner J, Whitfield P, Krebs J, et al. Nil whey protein effect on glycemic control after intense mixed-mode training in type 2 diabetes. Med Sci Sports Exerc. 2018;50:11-7.

39. Larsen AE, Bibby BM, Hansen M. Effect of a whey protein supplement on preservation of fat free mass in overweight and obese individuals on an energy restricted very low caloric diet. Nutr. 2018;10(12). https://doi.org/10. 3390/nu10121918.

40. Yang J, Wang HP, Tong X, Li ZN, Xu JY, Zhou L, et al. Effect of whey protein on blood pressure in pre- and mildly hypertensive adults: a randomized controlled study. Food Sci Nutr. 2019;7:1857-64.

41. Rakvaag E, Fuglsang-Nielsen R, Bach Knudsen KE, Landberg R, Johannesson Hjelholt A, Søndergaard E, et al. Whey protein combined with low dietary Fiber improves lipid profile in subjects with abdominal obesity: a randomized, Controlled Trial Nutrients. Nutr. 2019;11(9). https://doi.org/10. 3390/nu1 1092091.

42. Bendtsen LQ, Lorenzen JK, Bendsen NT, Rasmussen C, Astrup A. Effect of dairy proteins on appetite, energy expenditure, body weight, and composition: a review of the evidence from controlled clinical trials. Adv Nutr. 2013;4:418-38.

43. Mollahosseini M, Shab-Bidar S, Rahimi MH, Djafarian K. Effect of whey protein supplementation on long and short term appetite: a meta-analysis of randomized controlled trials. Clin Nutr ESPEN. 2017;20:34-40.

44. Rigamonti AE, Leoncini R, Casnici C, Marelli O, Col A, Tamini S, et al. Whey proteins reduce appetite, stimulate Anorexigenic gastrointestinal peptides and improve Glucometabolic homeostasis in young obese women. Nutr. 2019;11(2). https://doi.org/10.3390/nu11020247.

45. Badely M, Sepandi M, Samadi M, Parastouei K, Taghdir M. The effect of whey protein on the components of metabolic syndrome in overweight and obese individuals; a systematic review and meta-analysis. Diabetes Metabol Syndrome. 2019;13:3121-31.

46. Adams RL, Broughton KS. Insulinotropic effects of whey: mechanisms of action, recent clinical trials, and clinical applications. Ann Nutr Metabol. 2016;69:56-63.

47. Zhang JW, Tong X, Wan Z, Wang Y, Qin LQ, Szeto IM. Effect of whey protein on blood lipid profiles: a meta-analysis of randomized controlled trials. Eur $J$ Clin Nutr. 2016;70:879-85.

48. Christensen R, Lorenzen JK, Svith CR, Bartels EM, Melanson EL, Saris WH, et al. Effect of calcium from dairy and dietary supplements on faecal fat excretion: a meta-analysis of randomized controlled trials. Obes Rev. 2009; 10:475-86.

49. Cicero AFG, Fogacci F, Veronesi M, Grandi E, Dinelli G, Hrelia S, et al. Short-term hemodynamic effects of modern wheat products substitution in diet with ancient wheat products: a cross-over. Randomized Clin Trial Nutr. 2018;10(11). https://doi.org/10.3390/nu10111666.

50. Mortensen LS, Hartvigsen ML, Brader LJ, Astrup A, Schrezenmeir J, Holst JJ, et al. Differential effects of protein quality on postprandial lipemia in response to a fat-rich meal in type 2 diabetes: comparison of whey, casein, gluten, and cod protein. Am J Clin Nutr. 2009;90:41-8.

51. Chen Q, Reimer RA. Dairy protein and leucine alter GLP-1 release and mRNA of genes involved in intestinal lipid metabolism in vitro. Nutrition. 2009;25:340-9.

52. Zhang $X$, Beynen $A C$. Lowering effect of dietary milk-whey protein $v$. casein on plasma and liver cholesterol concentrations in rats. Br J Nutr. 1993;70:139-46.

53. El Khoury D, Anderson GH. Recent advances in dietary proteins and lipid metabolism. Curr Opin Lipidol. 2013;24:207-13.

54. Ohlsson L, Hertervig E, Jönsson BA, Duan RD, Nyberg L, Svernlöv R, et al. Sphingolipids in human ileostomy content after meals containing milk sphingomyelin. Am J Clin Nutr. 2010;91:672-8.

\section{Publisher's Note}

Springer Nature remains neutral with regard to jurisdictional claims in published maps and institutional affiliations.

Ready to submit your research? Choose BMC and benefit from:

- fast, convenient online submission

- thorough peer review by experienced researchers in your field

- rapid publication on acceptance

- support for research data, including large and complex data types

- gold Open Access which fosters wider collaboration and increased citations

- maximum visibility for your research: over $100 \mathrm{M}$ website views per year

At BMC, research is always in progress.

Learn more biomedcentral.com/submissions 